\title{
Benefits and costs of earwig (Forficula auricularia) family life
}

\author{
Mathias Kölliker
}

Received: 11 October 2006 /Revised: 24 January 2007 / Accepted: 12 February 2007 /Published online: 6 March 2007

(C) Springer-Verlag 2007

\begin{abstract}
The evolution of parental care and family group formation critically depends on offspring survival benefits and parental fecundity costs of care under given ecological conditions. Investigations of the functional significance of care in insect species that exhibit facultative parental care have been relatively rare but may be of particular interest for better understanding of benefit and cost schedules at an early evolutionary stage. In this study, aspects of benefits and costs of care were addressed in the sub-social European earwig (Forficula auricularia; Dermaptera: Forficulidae) by manipulating the presence of tending mothers and brood size in a fully crossed experimental design. Larvae growing in broods tended by their mother or of reduced size showed a higher survival probability than larvae growing in untended or large broods, as predicted if maternal care is beneficial and shaped by a trade-off between number and quality of offspring. Analysis of patterns of food consumption and developmental time further suggested that the benefit of maternal attendance is mediated by the maternal provisioning of food, while the quality-quantity trade-off seemed to be driven by sibling rivalry. Further, tending mothers delayed the production of a second clutch, indicating a potential cost of care in terms of lifetime fecundity. This study experimentally shows benefits and potential costs of maternal care and family group formation in the European earwig. More detailed behavioural experi-
\end{abstract}

Communicated by P. Moore

M. Kölliker $(\square)$

Zoological Institute, Evolutionary Biology, University of Basel, Vesalgasse 1,

4051 Basel, Switzerland

e-mail: mathias.koelliker@swissonline.ch ments will be required to fully understand how behavioural interactions among family members mediate these reproductive outcomes.

Keywords Sociality Parental care $\cdot$ Clutch size $\cdot$ Forficula auricularia $\cdot$ Life history trade-off

\section{Introduction}

The evolution of parental care requires conditions under which selection favoured an enhanced investment of resources by parents in individual offspring (Trivers 1972; Alexander 1974; Clutton-Brock 1991). Because this added per capita investment comes at the expense of the number of offspring that can be produced (Trivers 1972), parental care can only spread if the benefits of care, in terms of offspring survival and/or fecundity, outweigh the offspring number advantage of non-caring individuals. Such conditions may include harsh and unpredictable ecological environments due to the obvious benefits of care to offspring survival (Wilson 1971, 1975; Tallamy 1984; Tallamy and Wood 1986; Clutton-Brock 1991). However, parental care only evolves under these conditions if the experienced parental fecundity costs under these same conditions do not outweigh offspring benefits (Trivers 1972; Smith and Fretwell 1974; Clutton-Brock 1991).

The benefit/cost ratio likely depends not only on the external environmental conditions (ecology), but also on preexisting intrinsic aspects of an organism's life-history (i.e. "life-history preadaptations" sensu Tallamy and Wood 1986). For instance, enhanced investment in individual offspring has lower evolutionary costs in semelparous species because the whole lifetime reproduction is achieved in a single reproductive attempt (i.e. no trade-off with future reproduc- 
tion; Stearns 1992; Tallamy and Brown 1999). Further, aggregation of offspring (Ruxton and Sherratt 2006) in space and time (i.e. clutches as opposed to singly deposited eggs) may be a critical preadaptation facilitating the evolution of care provisioning. It reduces the costs involved in the initial evolution of care (Tallamy and Wood 1986) in particular because it allows the provisioning of "shared" benefits (Lazarus and Inglis 1986), that is, care that the parent can provide to the family group as a whole (e.g. defense against predation; Clutton-Brock 1991; Costa 2006).

A considerable number of studies have investigated benefits and costs involved in parental care in birds and mammals (see Partridge and Harvey 1988; Lindén and Møller 1989; Clutton-Brock 1991; Roff 1992; Stearns 1992 for reviews). Birds and mammals exhibit sophisticated, highly derived forms of parental care. Care is usually obligate, and offspring cannot survive without at least some care early in their life. As pointed out by Smiseth et al. (2003), this tight integration of parental care into the organism's life-history and development implies that experimental studies are limited to investigations of benefit and cost schedules maintaining care in the neighbourhood of this derived state.

Obligate care is less frequent in other groups of animals. Species with facultative care may be of particular interest for better understanding the early evolutionary conditions under which parental care evolved (Smiseth et al. 2003), but benefits and costs of parental care have been less studied in such systems (but see, e.g., Eggert et al. 1998; Smiseth et al. 2003; Zink 2003; Agrawal et al. 2005). For instance, sub-social insects (Wilson 1971; Costa 2006) form family groups through part or all of juvenile development, and usually the female (but sometimes the male or both parents; Trumbo 1996; Tallamy 2001) attends the clutch and provides care. The most common form of care is clutch attendance and the defence of eggs against predation and parasitism, but extended care including the provisioning of food to hatched larvae has evolved independently in various insect taxa (reviewed in Tallamy and Wood 1986; Trumbo 1996; Costa 2006). Care is often not obligate because larvae can survive without care by early nest leaving, dispersal, clutch-joining and/or independent foraging (Lamb 1976a,b; Vancassel 1984; Smiseth et al. 2003; Agrawal et al. 2004; Costa 2006; Kölliker and Vancassel 2007), implying that alternative survival strategies by larvae have been maintained (Smiseth et al. 2003).

In this study, I present an experimental study of benefits and costs of maternal care and family group formation in the European earwig (Forficula auricularia; Dermaptera: Forficulidae), a sub-social insect species where mothers tend their clutch of eggs and provision food to hatched larvae through the early instars (Lamb 1976a,b; Vancassel 1984). The functional significance of maternal attendance was addressed by manipulating both the presence of tending mothers and brood size in a fully crossed design. The aims of this study were to test the predictions that (1) Maternal attendance and care enhances offspring survival (benefit of care). (2) Offspring from small broods may benefit from an enhanced individual survival probability (offspring quantity/quality trade-off). (3) Female attendance of larvae reduces her future reproductive potential (cost of care). While previous studies on benefits and costs of parental care in sub-social insects manipulated either the presence of parents or clutch/brood size, the crossed design allowed me a fuller test also incorporating potential interactions between the presence of tending females and brood size. Such an interaction would indicate effects of the tending mother on the quantity/quality trade-off among her offspring. I further investigated how behaviours such as food consumption, maternal food provisioning and larval nest leaving and dispersal may mediate these reproductive outcomes.

\section{Materials and methods}

Earwig reproductive biology

The European earwig is a sub-social insect species where females tend clutches of eggs in soil burrows throughout winter. They continuously clean the eggs with their mouthparts, which seems to have the function of protecting the eggs from pathogenes (Weyrauch 1927; Lamb 1976a,b; Gingras and Tourneur 2001; Costa 2006). After hatching in early spring, females provision food to larvae through first instar and attend/defend the aggregated family group in the burrow and during nocturnal foraging excursions (Lamb 1976a,b; Vancassel 1984). European earwigs are omnivorous, consuming a wide range of animal and plant material (e.g. Costa 2006). A fraction of the reproducing females produces a second, much smaller, clutch in late spring (Vancassel 1984; Vancassel and Quris 1994; Gingras and Tourneur 2001). Larvae go through four larval instars before they reach the adult stage (Tomkins 1999). Earwigs are well known for the sexually dimorphic, conspicuous forceps (Briceño and Eberhard 1995), elongated and sclerotised (and in males elaborate, horn-like) cerci, which are used in courtship (Tomkins and Simmons 1998), as weapons in male-male competition (Moore and Wilson 1992; Radesäter and Halldórsdóttir 1993; Forslund 2003) and in defence against predators (Costa 2006).

General methods

The experiments were carried out in spring 2006. Adult European earwigs were collected in August/September 
2005 on an apple tree orchard in Gommiswald, Switzerland, located $5-10 \mathrm{~km}$ east from the east shore of Lake Zurich, at an altitude of approximately $550 \mathrm{~m}$ above sea level. The earwigs were caught using "cardboard belt traps", pieces of cardboard wrapped around tree trunks of high-stem apple trees that had not been treated with insecticides (the nocturnal earwigs like hiding inside the cardboard during the day). After transfer to the lab, mixed male/female groups of about 60 individuals (approx. 30 males/30 females) were housed in glass containers $(20 \times$ $30 \times 20 \mathrm{~cm}$ ) on moist sand as substrate, with clay pot pieces as shelter and pollen as food, and held under a $14 \mathrm{~h}: 10 \mathrm{~h}$ $\mathrm{L} / \mathrm{D}, 20^{\circ} \mathrm{C}: 15^{\circ} \mathrm{C}$ photoperiod/temperature schedule. When the first egg laying was observed on November 4th, we removed all females from the glass containers and set them up individually in Petri dishes $(100 \times 20 \mathrm{~mm})$ with moist sand as substrate and a plastic shelter. To terminate the diapause of the eggs, all females and their eggs were placed in an artificial winter at complete darkness and a temperature of $10^{\circ} \mathrm{C}$ for 1 month and $5^{\circ} \mathrm{C}$ afterwards. The decrease in temperature to $5^{\circ} \mathrm{C}$ was necessary because a few females were observed eating their eggs at $10^{\circ} \mathrm{C}$, indicating insufficient conditions for hibernation. Food was removed from the dishes as soon as females laid a clutch of eggs and changed twice a week for females that had not yet laid their clutch.

Females and their clutches were removed from the artificial winter between the 16th and 25th March, and the clutches were installed on a new photoperiod/temperature schedule of $16 \mathrm{~h}: 8 \mathrm{~h} \mathrm{~L} / \mathrm{D}, 20^{\circ} \mathrm{C}: 20^{\circ} \mathrm{C}$. Clutches were checked daily for hatching. One day after initiation of hatching of clutches (day 1), they were set up in larger Petri dishes $(150 \times 25 \mathrm{~mm})$. Watch glasses (diameter $40 \mathrm{~mm}$; VWR International AG, Dietikon, Switzerland) were used as shelters. The burrow/shelter consisted of a little crater manually formed into the sand that was covered by two such watch glasses put on top of each other. The top watch glass was painted with black acrylic paint. The setup with the watch glasses allowed us to see into the nest burrow by simply lifting the top (black) watch glass without causing disturbance inside the burrow. This method was modified from M. Vancassel (personal communication). Beer bottle caps, placed at a distance of about $5 \mathrm{~cm}$ from the burrow, were used as food containers (Agrawal et al. 2004; Kölliker et al. 2005).

To facilitate the transfer of the females and her larvae (nymphs) at hatching, broods of larvae were chilled on ice to reduce their activity (Agrawal et al. 2004). Based on the date of hatching, clutches were allocated randomly to sequences of four experimental treatments: (1) no tending female, brood size reduced by $50 \%$, (2) no tending female, full brood size, (3) tending female, brood size reduced by $50 \%$ and (4) tending female, full brood size. With an average hatching success of $91.1 \%$, the mean $( \pm \mathrm{SD})$ numbers of hatchlings before manipulation for each treatment were 49.71 (12.56), 51.17 (11.83), 49.14 (14.13) and 51.93 (11.63), respectively $\left(F_{3,111}=0.30, p=0.82\right)$, showing proper randomisation of brood sizes among treatments. After brood size manipulation, the mean $( \pm \mathrm{SD})$ number of hatchlings were 25.21 (6.18), 51.17 (11.83), 24.79 (7.28) and 51.93 (11.63) in the four treatments, respectively $\left(r^{2}=0.644, F_{3,111}=66.85, p<\right.$ 0.0001). Females of the non-tending treatments were separated from their brood and housed individually in Petri dishes to monitor their food consumption and laying of a second clutch. They were handled the same way as the attended family groups.

Food was provided as single pollen pellets in beer bottle caps. The pellets were placed on a piece of filter paper in the beer bottle caps to inhibit the pollen's tendency to liquefy under the humidity inside the Petri dishes. Pollen pellets were fabricated by dissolving pollen (regular flower pollen, Chrüterhüsli, Basel, Switzerland) in water to form a thick liquid. This solution was spread on a baking sheet and baked at $50^{\circ} \mathrm{C}$ for approximately $20 \mathrm{~min}$ to let the contained water partly evaporate, resulting in a "pollen dough" from which small disks (diameter about $5 \mathrm{~mm}$ ) were cut out. Mean $( \pm \mathrm{SD})$ weight of pollen pellets was $42.25 \mathrm{mg}$ (10.21 mg; $n=20)$.

\section{Data collection}

The food of all broods was changed daily. The quantity of consumed food per family group and day was determined by weighing the pollen pellets (including filter paper and beer bottle caps) when provided and when removed from the dish (to the nearest milligram; using a Mettler Toledo PG503-S DeltaRange ${ }^{\circledR}$ scale). Because the pollen pellets take up humidity in the Petri dishes, all the removed caps were dried for $15 \mathrm{~min}$ at $60^{\circ} \mathrm{C}$ in a drying oven and cleaned of sand using a paintbrush before weighing. The difference between the two weight measures ("after"-"before") reflects the quantity of pollen consumed by a family group during approximately $24 \mathrm{~h}$.

As a measure of larval nest leaving and dispersal, we counted the number of larvae found outside the nest burrow during the daily checks and measured the distance between the nest and the outermost larva of an aggregation of larvae. When several aggregations occurred, we used one such measure for each aggregated group. From this information, a "dispersal index" was computed as $n_{\text {aggreg }} / n_{\text {hatched }} \times$ distance, where $n_{\text {aggreg }}$ is the number of larvae in an aggregated group and $n_{\text {hatched }}$ the number of hatched larvae. Summing the multiple (if any) measures per brood per day and over the 8 days after hatching provided a measure of a brood's overall tendency to leave the nest and disperse. 
The analysis of food consumption and larval nest leaving is limited to the first 8 days after hatching, when all the broods still exclusively contained first instar larvae.

The number of days it took a brood from hatching until the first individual larva reached the fourth (i.e. final) larval instar was taken as a measure of developmental time. Larval survival was determined by counting the number of emerging fourth instar larvae and comparing it to the number of larvae initially (after setup at hatching) present.

To avoid the problem of females or their larvae consuming the eggs of the second clutch (Vancassel 1984), tending females were isolated from their first clutches on 19th April, which is $28 \pm 3.23$ (SD) days after hatching, and set up individually in new dishes where they were fed and watered as before. Females were kept until they laid their second clutch or died.

\section{Statistical analysis}

The total number of clutches involved in the experiment was 120. Five clutches had to be excluded due to early maternal and/or larval mortality. Tested variables were checked for normality and homogeneity of variance among treatments and transformed if required (food consumption was log transformed to achieve homoscedacity). The basic model structure used throughout (if not otherwise stated) contains the two experimental treatments (presence/absence of a tending mother, reduced/natural brood size) and their interaction as factors. The models were run using generalised linear models (PROC GENMOD; SAS 1999). With continuously and normally distributed dependent variables, the model was specified with a normal error distribution (i.e. analysis of variance; ANOVA). For proportional or categorical dependent variables (e.g. proportion of surviving larvae and the occurrence of a second clutch), a logit link function and binomial error distribution (i.e. logistic regression) was used to fit the model.

Food consumption patterns over consecutive days was analysed using multivariate ANOVA (MANOVA; PROC MIXED; SAS 1999), with the daily food consumption up to day 8 as repeated measure and the experimental treatments and their interaction as factors. Due to the heavily non-normal distribution of the larval dispersal index (strong positive skew), non-parametric Wilcoxon rank-sum/ Kruskal-Wallis tests were used to analyse the nest leaving data (PROC NPAR1WAY; SAS 1999).

Given the directionality of the predictions regarding the effect of maternal attendance and brood size on larval survival, and of maternal attendance on the production of second clutches (see "Introduction"), two-tailed ordered heterogeneity tests (OHT) following Rice and Gaines (1994) were used in these cases to account for the a priori directional expectation. Corresponding $p$ values are denoted as $p_{\text {ОНт }}$. All other tests are symmetrically two tailed.

\section{Results}

Benefits of family life: larval survival and developmental time

The presence of a tending mother significantly enhanced larval survival (Fig. 1a; logistic regression: $F_{1,110}=4.85$, $p_{\mathrm{OHT}}=0.019$ ), and larval survival was significantly higher in reduced broods (Fig. $1 \mathrm{a} ; F_{1,110}=4.17, p_{\mathrm{OHT}}=0.027$ ). The interaction between the two treatments was not significant $\left(F_{1,110}=0.06, p=0.80\right)$, suggesting that maternal attendance and brood size had independent (i.e. additive) effects on larval survival. Together, maternal attendance and brood size accounted for $7.8 \%$ of the deviance in larval survival.

Adding food consumption (see below) as a covariate to the model revealed a positive correlation between larval survival and family group food consumption $\left(F_{1,109}=5.53, p=0.021\right)$. With food consumption in the model, maternal attendance was no longer significant $\left(F_{1,109}=0.71, p=0.40\right)$, while the effect of brood size remained significant $\left(F_{1,109}=9.38, p=\right.$ 0.003 ). The estimated logistic regression equation (holding treatment effects constant) was: Logit(survival) $=-0.2111$
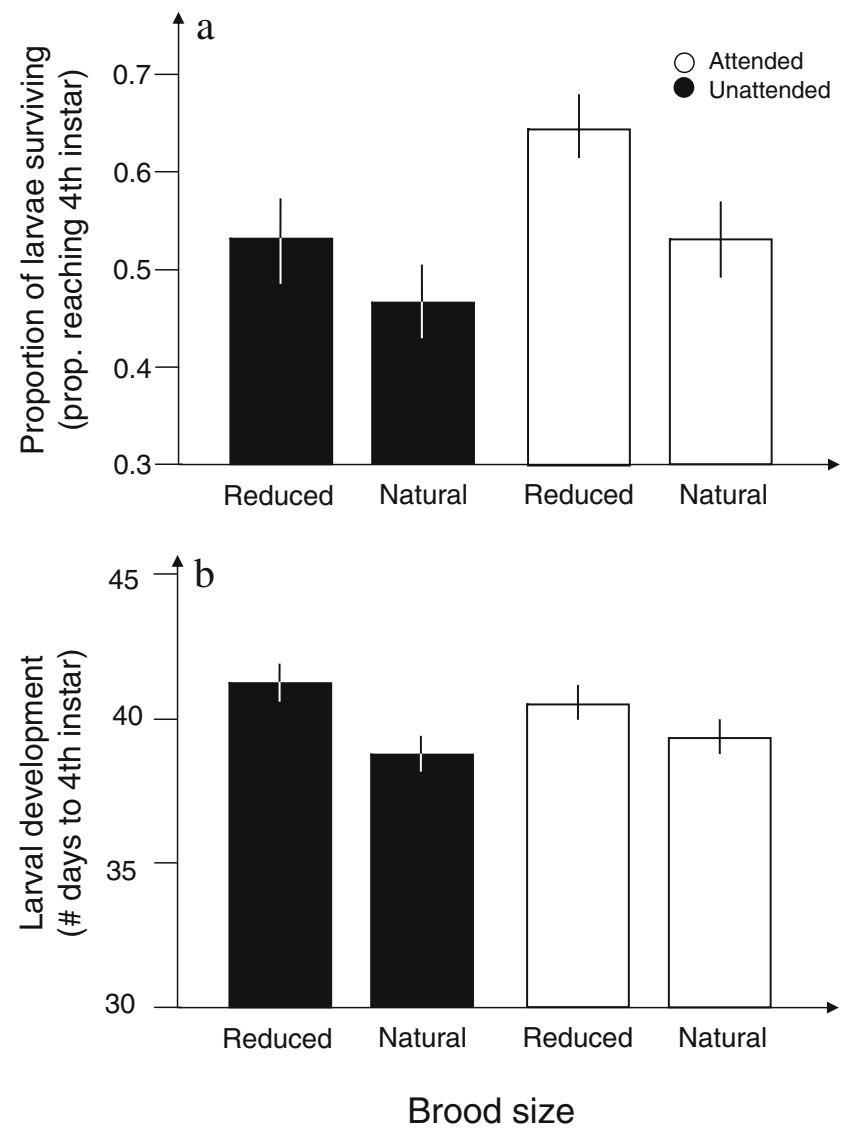

Fig. 1 Effects of maternal attendance and brood size on the proportion of larvae surviving (a) and developmental time (b). Shown are means \pm SE. Black bars: unattended broods (females removed); white bars: maternally attended broods 
Table 1 Effect of maternal brood attendance on the frequency and size of second clutches, and the inter-clutch interval (time between hatching of first and laying of second clutch)

\begin{tabular}{|c|c|c|c|c|}
\hline & Non-tending females (mean \pm SE) & Tending females (mean \pm SE) & Test statistic & $p_{\mathrm{OHT}}$ \\
\hline Second clutch freq. & 0.333 & 0.362 & $\phi_{1}^{2}=0.10^{\mathrm{a}}$ & 0.75 \\
\hline Second clutch size (\# eggs) & $16.74(1.68)$ & $14.62(1.99)$ & $F_{1,38}=0.65^{\mathrm{b}}$ & 0.27 \\
\hline Second clutch intrvl. (\# days) & $32.47(1.03)$ & $39.71(1.78)$ & $F_{1,38}=12.50^{\mathrm{b}}$ & $<0.001$ \\
\hline
\end{tabular}

${ }^{\text {a }}$ Logistic regression

${ }^{\mathrm{b}}$ ANOVA

$(0.2364 \mathrm{SE})+0.0092(0.0039 \mathrm{SE}) \times$ food consumption (in milligrams per 8 days after hatching).

In terms of absolute numbers, the positive effect of female attendance on larval survival (Fig. 1a) translated into a significantly larger absolute number of fourth instar larvae (ANOVA: $F_{1,110}=4.30, p_{\mathrm{OHT}}=0.026$ ). The higher larval survival in reduced broods (Fig. 1a) was not sufficient to counter the experimental $50 \%$ reduction in brood size at hatching. Reduced broods still contained a significantly smaller absolute number of fourth instar larvae $\left(F_{1,110}=42.71, p_{\mathrm{OHT}}<0.001\right)$. Again, the effects of maternal attendance and brood size did not significantly depend on each other (interaction term: $F_{1,110}=0.64, p=0.43$ ).

The presence of a tending mother had no significant effect on larval developmental time (Fig. 1b; ANOVA: $\left.F_{1,110}=0.01, p=0.92\right)$. Conversely, larvae in reduced broods developed significantly more slowly (Fig. $1 \mathrm{~b} ; F_{1,110}=9.55$, $p=0.003$ ) than larvae in naturally sized broods, an effect that was not significantly modified by the presence of a tending mother (interaction term: $F_{1,110}=1.48, p=0.23$ ).

Costs of family life: female future reproduction

Non-tending females that were isolated from their clutch at hatching did not have a higher likelihood of producing a second clutch than tending females (Table 1), and the size of second clutches was not significantly larger (Table 1). However, the inter-clutch interval, defined here as the number of days between hatching of the first and laying of the second clutch, was significantly shorter for non-tending females (by about 1 week; Table 1). Within the group of tending females, the experimental brood size had no significant effects on the frequency, size or time interval (all $p>0.41$ ).

Family group food consumption

Food consumption of family groups significantly depended on the age of the larvae (Fig. 2; MANOVA: $F_{7,111}=33.91$, $p<0.001$ ) with a peak occurring around days 2-4 after hatching (Fig. 2). As expected, female-tended family groups consumed significantly more food than unattended ones (Fig. 2; $F_{1,111}=46.94, p_{\mathrm{OHT}}<0.001$ ), an effect that contains not only maternal food provisioning to larvae but also larval and female self-feeding.

Reduced broods consumed significantly less food than naturally sized broods (Fig. $2 ; F_{1,111}=62.98, p_{\mathrm{OHT}}<0.001$ ). The significant interactions between larval age and both maternal attendance $\left(F_{7,111}=3.08, p=0.005\right)$ and brood size $\left(F_{7,111}=3.05, p=0.006\right)$ demonstrate that the presence of a tending mother and the size of a brood both affected daily food consumption patterns through first larval instar. The non-significant interaction between maternal attendance and brood size $\left(F_{1,111}=1.91, p=0.17\right)$ suggests that tending mothers did not modify the food consumption in relation to family group size. Further, the daily pattern of food consumption did not depend on an interaction between maternal attendance and brood size (three-way interaction: $\left.F_{1,111}=0.50, p=0.83\right)$.

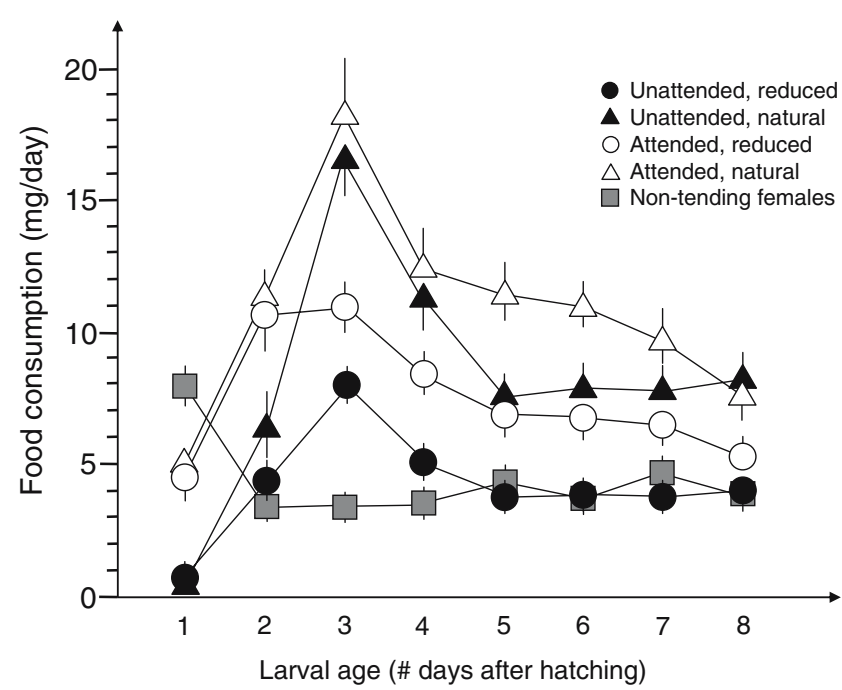

Fig. 2 Effects of maternal attendance and brood size on daily patterns of food consumption by earwig family groups. Black symbols: unattended broods; white symbols: maternally attended broods; circles: reduced broods; triangles: naturally sized broods. Shown are per day means \pm SE of the quantity of pollen $(\mathrm{mg})$ consumed per treatment group. Food consumption of non-tending females (separated from their broods at hatching) is also shown (grey squares) as a control for the food consumption a female. Note that this control can only be taken as an upper limit of female self-feeding (see "Discussion" for details) 
The food consumption of a family group was proportional to its size, as can be seen in Fig. 2, where the unattended reduced brood treatment (black circles) is almost exactly at $50 \%$ of the consumed food of unattended naturally sized brood (black triangles). Confirming this visual inspection of Fig. 2, per capita food consumption of larvae was statistically not different between reduced and naturally sized unattended groups of larvae $\left(F_{1,55}=0.08, p=\right.$ $0.77)$. This comparison is not directly possible in the female-tended treatments because the self-feeding by the females distorts the proportionality of food consumption relative to larval number. However, the lack of a significant interaction between female attendance and brood size ( $p=$ 0.17 , see above) indicates that the proportionality of food consumption relative to brood size seems to hold for tended family groups as well.

\section{Larval nest leaving}

There was an overall significant difference among the four treatment groups in larval nest leaving/dispersal behaviour (Fig. 3; Kruskal-Wallis test: $\chi_{3}^{2}=18.91, p<0.001$ ). This effect was due to the maternal attendance treatment: The presence of a tending mother significantly reduced the incidence of nest leaving (Fig. 3; Wilcoxon rank-sum test: $n=115 ; z=4.23, p<0.001)$. Brood size had no significant influence (Fig. 3; Wilcoxon rank-sum test: $n=115 ; z=0.73$, $p=0.46$ ).

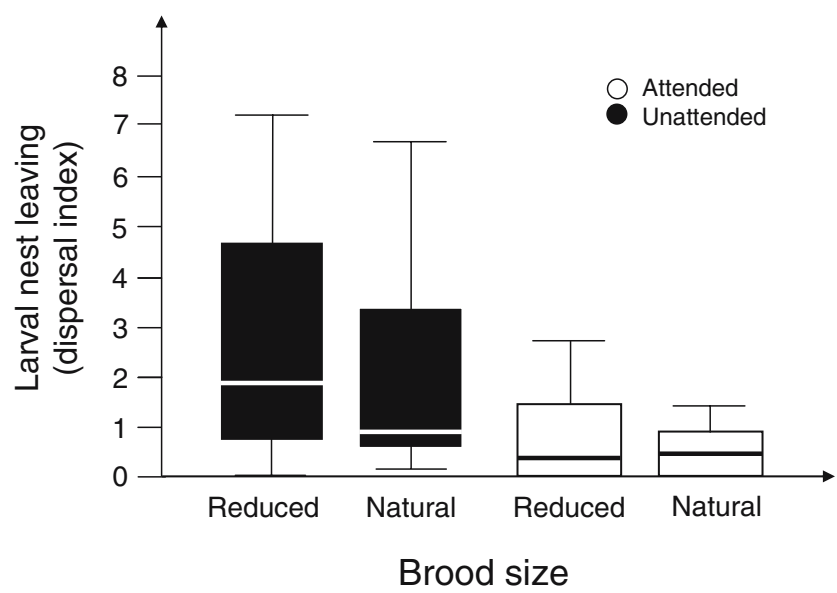

Fig. 3 Boxplots illustrating the effects of maternal attendance and brood size on larval nest leaving. Black boxes: unattended broods; white boxes: maternally attended broods. The medians and quartiles of the dispersal index are depicted by the box, and the whiskers represent the data point closest to $1.5 \times$ the interquartile range (SAS 1999). The dispersal index is a compound measure of nest leaving incorporating the proportion of larvae of a brood found outside the nest and the distance from the nest (see "Materials and methods")

\section{Discussion}

Benefits and costs of family group formation were tested in European earwigs using a fully crossed experiment manipulating the presence of tending mothers and the number of larvae in a family group. The focus was on functional aspects of post-hatching parental care, the period of care when offspring have the potential to actively influence patterns and quantities of care. The extended period of earwig egg care, lasting several weeks through winter, has also been studied in different species. Egg care was shown to be beneficial in terms of hatching success in $F$. auricularia (Weyrauch 1927; see Costa 2006) and costly in terms of future reproduction in the ring-legged earwig Euborellia annulipes (Rankin et al. 1996) and other social insect species (see Agrawal et al. 2005).

\section{Benefits of care}

As expected, both maternal attendance and family group size significantly affected larval survival in European earwigs. Tending mothers and smaller broods had positive effects on larval survival, but the underlying mechanisms producing these two effects differed. Under the conditions of this study (i.e. ad libitum food, exclusion of predation), tending mothers most likely enhanced larval survival by the provisioning of food (Lamb 1976a,b; Vancassel 1984; Liu 1991). Unfortunately, food consumption could only be quantified on the family group level, confounding food provisioning and larval/female self-feeding. The food consumed by isolated females was quantified as a potential correction for female self-feeding, but food intake of isolated females likely overestimates the self-feeding of brood-tending mothers. Isolated females had no possibility to regurgitate ingested food to larvae (Shepard et al. 1973), and their physiological state probably quickly deviated from the state of tending females (Vancassel 1984; Trumbo 1996). Nevertheless, indirect evidence on food consumption supported the interpretation that food provisioning was the prime aspect of care mediating the benefit of maternal attendance in the present study. Entering the food consumption of a family group into the statistical model revealed that the beneficial effect of maternal attendance on larval survival was fully explained by variation in food consumption, while the effect of brood size remained significant (and even became somewhat stronger).

With regard to the brood size effect, mean per capita food consumption was the same in small and large unattended family groups, demonstrating that differential mortality in small and large broods was not mediated by a different average food intake (as would have been expected under limited food). The lower survival of larvae in larger broods can possibly be explained by more intense larval 
rivalry in larger broods, resulting in a more skewed distribution of the consumed food among family group members (without altering average per capita food consumption) and differential starvation favouring the survival of more competitive larvae. The observed faster development in larger broods (Fig. 1b) is consistent with this hypothesis because faster development is an expected consequence of sibling rivalry (Mock and Parker 1997; Bonabeau et al. 1998; Royle et al. 1999), and faster development usually entails survival costs (Partridge and Harvey 1988; Roff 1992; Stearns 1992).

Contrary to the overall brood size effect, tending mothers enhanced larval survival without affecting developmental time, and they did not compensate for the reduced survival and/or faster development of larvae in larger broods (i.e. none of the maternal attendance $\times$ brood size interactions were statistically significant). Thus, earwig mothers, likely through their food provisioning, might shift upward the survival-developmental time trade-off line of their larvae (without altering its slope), resulting in higher larval survival for any given developmental time. The data suggest a role for mothers in the within-brood distribution of food, by possibly countering rivalry-driven food intake skew among larvae. Detailed observations of maternal food allocation will be required to fully understand the behavioural nature of the beneficial effect of maternal attendance on larval survival.

The presence of a tending mother had a direct consequence on larval nest leaving behaviour. Tended larvae left their nest much less, a result that confirms a recent field study in the same species (Kölliker and Vancassel 2007). This result is in line with the hypothesis that it may be adaptive for unattended sub-social insect larvae to leave the nest early, disperse to forage independently or join (and ideally get adopted by) other intact family groups (Agrawal et al. 2004; Suzuki et al. 2005; Kölliker and Vancassel 2007). A recent study in the hump earwig Anechura harmandi showed that the early larval dispersal triggered by maternal absence was due to the resulting food shortage. When food was experimentally added, larval dispersal could be restored to the usual level even in the absence of the mother (Suzuki et al. 2005). In the present study, independent foraging by larvae seemed to be quite efficient (note that, to attain the food source, larvae had to leave the burrow). Unattended broods consumed about as much food as tended broods of same size. This can be seen by adding the food consumption of an isolated female to the intake of an unattended family group of the same brood size treatment in Fig. 2 (although part of the food intake measured for isolated females probably needs to be taken as food provisioning in tending mothers; see above). It may be expected that early larval dispersal is less efficient under natural conditions when food is limited (e.g. food sources are difficult to locate and/or hard to reach for larvae), and predation may add significant costs to early dispersal (Kölliker and Vancassel 2007).

\section{Costs of care}

Costs of care have now been studied in an increasing number of (sub-) social insect species (e.g. Vancassel 1984; Zink 2003; Agrawal et al. 2005; Field et al. 2007; see Costa 2006 for a review). In the present study, female European earwigs tending hatched larvae laid their second clutch about 1 week later than females that were not exposed to larvae. While the expected reduction in the frequency and the size of second clutches was not supported by the data, previous female-removal studies in this species showed such effects (Vancassel 1980, 1984; Vancassel and Foraste 1980). A possible explanation for this discrepancy may be the different food qualities used in the experiments. That diet influences the egg-laying capacity of earwig females has previously been demonstrated in the related species Forficula senegalensis (Boukary et al. 1998). Vancassel and his coworkers used in their studies either protein-poor carrots or a carrot-pollen mixture (Vancassel 1984) and found costs of maternal attendance in terms of the frequency and size of second clutches. In the present study, pure pollen was used, which is very protein rich. The critical resource for egg production (i.e. protein) may thus have been less limited in the present than in previous studies. Nevertheless, tending females delayed the production of their second clutch even under the protein-rich conditions of the present study. While an extended inter clutch interval per se does not necessarily reflect an evolutionary reproductive cost, such a delay most likely reduces the reproductive value of second clutches under natural conditions. The "effective reproductive value" (Stearns 1992) of a second clutch is the size of the clutch weighed by the likelihood that the female reaches the age to lay that clutch. The longer the delay, the lower the likelihood that the female will survive to produce the clutch and, hence, its effective reproductive value. Under laboratory conditions, the approximate 1-week difference between tending and non-tending females did not translate into substantial survival differences, but under field conditions, a 1-week difference may be relevant.

The benefits and costs of care partly depend on the ecological conditions under which care is performed (Clutton-Brock 1991, see "Introduction"). Because the experiments were done under favourable laboratory conditions (i.e. ad libitum food, absence of predation), potentially critical resource limitations mediating benefits and costs of reproduction were absent. The results therefore provide conservative estimates of both benefits and costs of care (Agrawal et al. 2005) that may be largely due to factors 
intrinsic to the interactions among family members. As an example: The effect that tending eggs and/or hatched larvae results in delayed future reproduction has been repeatedly demonstrated in an increasing number of sub-social insect species (see Agrawal et al. 2005 for a review). Such a delay in the production of second clutches has also been reported in the Dermapteran species $F$. auricularia (Vancassel and Foraste 1980; Vancassel 1984; this study) and E. annulipes (Rankin et al. 1996). This delay may be directly caused by the interaction (behavioural or other) with the larvae. Larvae, through unknown cues, seem to have direct effects on maternal endocrinology (reviewed in Trumbo 1996) and, hence, the mother's tendency to care and capacity to lay a second clutch (Vancassel 1984).

In summary, this study provides experimental evidence for benefits and potential trade-offs and costs of family group formation and maintenance in the sub-social European earwig. The data suggest that maternal food provisioning and sibling rivalry are critical behavioural mechanisms mediating these benefits and costs. Detailed behavioural experiments will be required to fully understand how family interactions influence the reproductive outcomes found.

Acknowledgements I thank Michel Vancassel for his advice and for sharing his expertise on earwig biology and Anja Lahusen and Heinrich Höhn of Agroscope FAW Wädenswil for providing the adult earwigs used in the experiments. Allen Moore, Ralph Dobler, Flore Mas and an anonymous referee made valuable comments on the manuscript. Geneviève Kölliker, Regine Salathé and Michael Staerkle, as well as Adrian Baumeyer, Nicolas Boileau, Daniela Brites, Sabrina Gaba, Sandra Lass and Olivia Roth helped with animal husbandry during the experiments. The study was financially supported by the Swiss National Science Foundation (grant no. 3100A0-111969).

\section{References}

Agrawal AF, Brown JM, Brodie ED III (2004) On the social structure of offspring rearing in the burrower bug, Sehirus cinctus (Hemiptera: Cydnidae). Behav Ecol Sociobiol 57:139-148

Agrawal AF, Combs N, Brodie ED III (2005) Insight into the costs of complex maternal care behavior in the burrower bug (Sehirus cinctus). Behav Ecol Sociobiol 57:566-574

Alexander RD (1974) The evolution of social behavior. Ann Rev Ecolog Syst 5:325-383

Bonabeau E, Deneubourg J-L, Theraulaz G (1998) Within-brood competition and the optimal partitioning of parental investment. Am Nat 152:419-427

Boukary IB, Gingras J, Tourneur J-C (1998) Influence of diet on oviposition and survival of Forficula senegalensis Serville (Dermaptera: Forficulidae). Can Entomol 130:163-167

Briceño RD, Eberhard WG (1995) The functional morphology of male cerci and associated characters in 13 species of tropical earwigs. Smithsonian Contributions to Zoology, 535. Smithsonian Institute Press, Washington

Clutton-Brock TH (1991) The evolution of parental care. Princeton University Press, Princeton

Costa JT (2006) The other insect societies. Harvard University Press
Eggert A-K, Reinking M, Müller JK (1998) Parental care improves offspring survival and growth in burying beetles. Anim Behav 55:97-107

Field J, Turner E, Fayle T, Foster WA (2007) Costs of egg-laying and offspring provisioning: multifaceted parental investment in a digger wasp. Proc R Soc Lond B 274:445-451

Forslund P (2003) An experimental investigation into status-dependent male dimorphism in the European earwig, Forficula auricularia. Anim Behav 65:309-316

Gingras J, Tourneur J-C (2001) Timing of adult mortality, oviposition, and hatching during the underground phase of Forficula auricularia (Dermaptera: Forficulidae). Can Entomol 133:269-278

Kölliker M, Vancassel M (2007) Maternal attendance and the maintenance of family groups in common earwigs (Forficula auricularia): a field experiment. Ecol Entomol 32:24-27

Kölliker M, Chuckalovcak JP, Brodie ED III (2005) Offspring chemical cues affect maternal provisioning in burrower bugs (Sehirus cinctus). Anim Behav 69:959-966

Lamb RJ (1976a) Dispersal by nesting earwigs, Forficula auricularia (Dermaptera: Forficulidae). Can Entomol 108:213-216

Lamb RJ (1976b) Parental behavior in the Dermaptera with special reference to Forficula auricularia (Dermaptera: Forficulidae). Can Entomol 108:609-619

Lazarus J, Inglis IR (1986) Shared and unshared parental investment, parent-offspring conflict and brood size. Anim Behav 34:17911804

Lindén M, Møller AP (1989) Costs of reproduction and covariation of life history traits in birds. Trends Ecol Evol 4:367-370

Liu Z (1991) Le groupement familial chez Forficula auricularia L. (Insecte, Dermaptère): étude causale et fonctionnelle. Ph.D. thesis. Université de Rennes I, Rennes, France

Mock DW, Parker GA (1997) The evolution of sibling rivalry. Oxford University Press, Oxford

Moore AJ, Wilson P (1992) The evolution of sexually dimorphic earwig forceps: social interactions among adults of the toothed earwig, Vostox apicedentatus. Behav Ecol 4:40-48

Partridge L, Harvey PH (1988) The ecological context of life history evolution. Science 241:1449-1455

Radesäter T, Halldórsdóttir H (1993) Two male types of the common earwig: male-male competition and mating success. Ethology 95:89-96

Rankin SM, Storm SK, Pieto DL, Risser AL (1996) Maternal behavior and clutch manipulation in the ring-legged earwig (Dermaptera: Carcinophoridae). J Insect Behav 9:85-103

Rice WR, Gaines SD (1994) Extending nondirectional heterogeneity tests to evaluate simply ordered alternative hypotheses. Proc Natl Acad Sci USA 91:225-226

Roff DA (1992) The evolution of life histories. Chapman \& Hall, New York

Royle NJ, Hartley IR, Owens IPF, Parker GA (1999) Sibling competition and the evolution of growth rates in birds. Proc R Soc Lond B 266:923-932

Ruxton GD, Sherratt TN (2006) Aggregation, defence and warning signals: the evolutionary relationship. Proc R Soc Lond B 273:2417-2424

SAS (1999) SAS for Windows, Version 8.02. SAS Institute, Cary

Shepard M, Waddill V, Kloft W (1973) Biology of the predaceous earwig Labidura riparia (Dermaptera: Labiduridae). Ann Entomol Soc Am 66:837-841

Smiseth PT, Darwell CT, Moore AJ (2003) Partial begging: an empirical model for the early evolution of offspring signalling. Proc R Soc Lond B 270:1773-1777

Smith CC, Fretwell SD (1974) The optimal balance between size and number of offspring. Am Nat 108:499-506

Stearns SC (1992) The evolution of life histories. Oxford University Press, Oxford 
Suzuki S, Kitamura M, Matsubayashi K (2005) Matriphagy in the hump earwig, Anechura harmandi (Dermaptera: Forficulidae), increases the survival rates of the offspring. J Ethol 23:211213

Tallamy DW (1984) Insect parental care. BioScience 34:20-24

Tallamy DW (2001) Evolution of exclusive paternal care in arthropods. Annu Rev Entomol 46:139-165

Tallamy DW, Brown WP (1999) Semelparity and the evolution of maternal care in insects. Anim Behav 57:727-730

Tallamy DW, Wood TK (1986) Convergence patterns in subsocial insects. Annu Rev Entomol 31:369-390

Tomkins JL (1999) The ontogeny of asymmetry in earwig forceps. Evolution 53:157-163

Tomkins JL, Simmons LW (1998) Female choice and manipulations of forceps size and symmetry in the earwig Forficula auricularia L. Anim Behav 56:347-356

Trivers RL (1972) Parental investment and sexual selection. In: Campbell B (ed) Sexual selection and the descent of man. Aldine Publishing Company, Chicago, pp 136-181
Trumbo ST (1996) Parental care in invertebrates. Adv Study Behav 25:3-51

Vancassel M (1980) Importance des contacts entre la femelle et les larves chez quelques Dermaptères. Biol Behav 5:269-280

Vancassel M (1984) Plasticity and adaptive radiation of Dermapteran parental behavior: results and perspectives. Adv Study Behav 14:51-80

Vancassel M, Foraste M (1980) Parental behavior in Dermaptera. Reprod Nutr Dev 20:759-770

Vancassel M, Quris R (1994) Differential release of diapause in the earwig Forficula auricularia as indicator of respective contribution of two cohorts to the reproductive generation. Acta Oecol 15:63-70

Weyrauch WK (1927) Experimentelle Analyse der Brutpflege des Ohrwurmes Forficula auricularia L. Biol Zentbl 49:553-558

Wilson EO (1971) Insect societies. Harvard University Press, Cambridge Wilson EO (1975) Sociobiology: the new synthesis. Harvard University Press, Cambridge

Zink AG (2003) Quantifying the costs and benefits of parental care in female treehoppers. Behav Ecol 14:687-693 